\title{
The Development of State Regulation in Small Entrepreneurship Infrastructure Provision
}

\author{
Kalenskaya N.V. \\ Kazan Federal University, Kazan, 420008, Russia
}

\author{
Ahmetshin R.M. \\ Kazan Federal University, Kazan, 420008, Russia
}

Grigoryeva L.L.

Lecturer at Kazan (Volga Region) Federal University, Email: leona212@mail.ru

\section{Doi:10.5901/mjss.2014.v5n18p27}

\begin{abstract}
The article discusses the current state of the institutional infrastructure of small business at regional level, highlighted trends in the development of small business and enterprise infrastructure components market. The article comprises a set of theoretical and methodological statements and practical development of infrastructure and realization of entrepreneurship. The characteristics of entrepreneurship with expenses development and transactions based on the analysis highlighted the problem areas and suggested measures to overcome them.
\end{abstract}

Keywords: infrastructure, infrastructure of regional development, entrepreneurship, systems of government regulation, transactions.

\section{Introduction}

Priority tendency of the state regulation of socio-economic development in Russian Federation directed toward switch of progressive dynamics from the effective to the innovative type, at present is the formation of infrastructural complex as the basis for the entrepreneurial activity fostering. Priority of the given tendency is caused by the fact that under the present institutional conditions, barriers incoming in the branch in most economic sectors are prohibitively high for small and big business enterprises which, according to Russia's development strategy until 2020, should become a basis for the provision of positive progressive dynamics. At the same time high index of the above named barriers are in a large degree caused by the lack of development in transport, innovation, logistics, financial and business management infrastructures, the influence of which increases by polarization of economic space, followed by gradual decrease in the entrepreneurial activity at early stages of business development, i.e. gradual decrease in the small business enterprises' share in the general amount of entrepreneurial units. Thus, the formation of infrastructural complex corresponding to the necessities of small business and taking into account the space polarization along with the disproportion of national socio-economic system is at the present time a priority task of the state regulation of the entrepreneurial activity.

Necessity to form the conditions for the effective development of small business increases in connection to Russia's entrance in WTO that causes the enhancement of market competition and as a result reduces small business competitiveness because of the additional enhancement of incoming barriers not in the last place being determined by relatively low level of infrastructure development. The state's interest in the given case is caused by small enterprises being key tax payers at the municipality budget level which at present experience considerable difficulties in budget balancing provision and also the necessity of the conditions formation for polarization of economic space smoothing which is also to a large extent caused by the tendencies of small business development. As it was proved by the analysis of the world experience in the creation of conditions for the maximum favour of small business enterprises development, the most effective instruments of regulation in strategic perspective being investments in infrastructure, since their development is one of the key stimuli for the entrepreneurial activity enhancement of the economic unit's life cycle at early stages.

This fact caused the necessity to conduct research on the possibilities and priority tendencies in state regulation of resource provision, necessity to form the effective instrumentation and mechanisms for the development of state 
regulation system at different levels of hierarchical management that was the reason for the given urgent research, its theoretical and practical importance at modern stage of Russian economic development.

\section{Theory}

Within the research work analysis of theoretical approaches to the provision of entrepreneurial development was conducted which showed that from the point of the effective provision of the given sphere state regulation it is expedient to use the model Entrepreneurial Canvas as a basis for the frame construction developed at the University of Maryland. The mentioned model allows to provide clear differentiation between the internal and external small business environment that was a reason for its choice as a methodological platform of the thesis. According to this approach, distribution of infrastructural types by model elements was made that allowed to structure the types of infrastructural provision that correspond to the separate elements of small entrepreneurship development (Fig.1).

As it is clear from the picture definite infrastructural type corresponds to each element of OEC the presence of which allows to form conditions for the appropriate element development of the chosen frame construction of entrepreneurship stimulating. And it is clear that the creation and use of infrastructural elements have the greatest impact on the change of small business external environment (external entrepreneurial company's environment, specificities and modern state of the branch, competition, creation of consumer valuables and entrepreneurial opportunity) that is caused by great opportunities in state regulation in the mentioned spheres. At the same time in order to enhance the efficiency of state regulation of small entrepreneurship provision it is necessary to consider that a set of infrastructural types (social, innovative and management) form conditions for stimulating the entrepreneur's inner motives with absence of which the enhancement of entrepreneurial activity seems impossible.

\begin{tabular}{|c|c|c|c|c|c|}
\hline \multicolumn{2}{|c|}{$\begin{array}{l}\text { Entrepreneurial thinking } \\
\text { Social infrastructure }\end{array}$} & \multicolumn{2}{|c|}{$\begin{array}{l}\text { Entrepreneur's motivation } \\
\text { Innovative infrastructure }\end{array}$} & \multicolumn{2}{|c|}{$\begin{array}{l}\text { Entrepreneur's behavior } \\
\text { Management (administrative) } \\
\text { social infrastructure }\end{array}$} \\
\hline \multirow{2}{*}{$\begin{array}{l}\frac{\text { External medium }}{\text { of entrepreneurial }} \\
\text { company } \\
\text { Engineering } \\
\text { infrastructure }\end{array}$} & \multicolumn{2}{|c|}{$\begin{array}{l}\text { Branch specificities } \\
\text { Information infrastructure }\end{array}$} & \multicolumn{2}{|c|}{$\begin{array}{l}\text { Competition } \\
\text { Management } \\
\text { infrastructure }\end{array}$} & \multirow{2}{*}{$\begin{array}{l}\text { Entrepreneurial } \\
\text { opportunity } \\
\text { Information } \\
\text { infrastructure } \\
\text { Management } \\
\text { infrastructure } \\
\text { Innovative } \\
\text { infrastructure }\end{array}$} \\
\hline & \multicolumn{2}{|c|}{$\begin{array}{l}\text { Present state of the } \\
\text { branch } \\
\text { Production infrastructure } \\
\text { Transport infrastructure }\end{array}$} & \multicolumn{2}{|c|}{$\begin{array}{l}\frac{\text { Creation of consumer }}{\underline{\text { values }}} \\
\text { Production infrastructure }\end{array}$} & \\
\hline
\end{tabular}

Fig. 1. Typology of small entrepreneurship infrastructural types in regard to OEC elements

Thus, the key task for state regulation is the creation of infrastructural complex influence which is not limited to the development of external entrepreneurial medium that dictates the necessity of the first and foremost influence upon such OEC elements as entrepreneurial thinking, entrepreneur's motivation and behavior in the development of which the key role belongs to the gradual dynamics of social infrastructure.

\section{Results}

In the process of decision taking on the choice of key tendencies in state regulation of small business infrastructural provision one of the most important tasks is the evaluation of economic activity and exposure of the creation and development of infrastructural elements sequence which allows to determine priority sequence of investment realization in the small business infrastructure. Owing to this fact, it is necessary to determine the level and sequence of infrastructural development at which its creation, modernization and use by units of small entrepreneurship will be repaid. For the solution of such a task comparative analysis of investment efficiency in the development of infrastructure was conducted on the basis of data analysis on Volga federal district regions on the basis of which at the first stage potential joint expenditures for the creation and development of complex small business infrastructure were determined, calculated as weighed by the level of entrepreneurship development average level of expenditures on infrastructure from the point of 
element-by-element view in different regions and additional gross regional product. Furthermore, on the basis of the comparison of small business infrastructural development an appropriate level of TEA indicator (the level of entrepreneurial activity at initial stage defined by Global Entrepreneurship Monitor methodology) was determined as a key indicator of small entrepreneurship development level on the basis of which potential increase in gross regional product caused by the rise of entrepreneurial activity in the small entrepreneurship sector. Moreover, with the help of expert evaluation methods it was determined that while using not separate infrastructural elements of small entrepreneurship but a complex of infrastructural elements with inclusion of each additional element in the processes of small business development, gradually increasing positive synergetic effect rises which should also be considered at evaluation of the small entrepreneurship infrastructural creation and development determined as the accompanying rise of gross regional product. The effect being obtained in the format of gross regional product increase was estimated as total for the threeyear period which allows to compare the above mentioned expenditures with results by time factor. Results of comparison of the above mentioned expenditures with the results in element-by-element view on infrastructural undersystems are presented in Fig. 2.

In figure 2 two sequences of the creation and development of infrastructure are presented, the traditional sequence being presented on the left in which infrastructure is developing starting from production and transport to information, whereas on the right the process of infrastructure formation in accordance to the model OEC is presented, within which, in the first place, infrastructural elements directed towards stimulating of the small business internal environment development are created, i.e. infrastructure is created and developed in direction from social and innovative towards logistic.
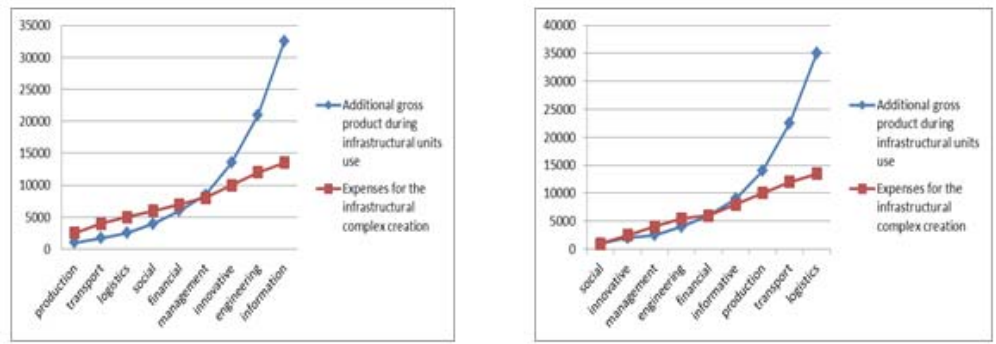

Fig. 2. Correlation of total expenses and results connected with the creation, development and use of small entrepreneurship infrastructure (increasing result)

From the data presented it is clear that in both cases full cost recovery of complex entrepreneurship infrastructure in three-year period occurs only in case when not less than 6 types of infrastructural units are created and used, and in the second case when infrastructure formation begins from the social one, full cost recovery occurs in case of less total initial investments (within the conducted conventional evaluation for investments slightly higher than 6.5 billions of roubles that is by 0.5 billions roubles lower than at realization of traditional approach to infrastructure formation). Moreover, based on the application of OEC model the approach allows to reach by $10 \%$ higher total result with formation of complex nineelement small business infrastructure that is an evidence of the expediency of the suggested approach use to the state regulation of the infrastructure sequence development being considered.

As it was shown in the conducted in the process of the thesis research analysis of the functioning system of state regulation of small entrepreneurship infrastructural provision, at present management of different infrastructural elements is conducted by different state agencies that, on the one hand, provides the formation of the required branch infrastructure, on the other hand, causes unbalance of its development. Realization of such an approach leads to overexpenditure of state resources by two main reasons: the first, distribution of the accompanying authorities and responsibility between complexes of different state institutes regulating the small business development often leads to their duplication and expenditure of resources by different bodies of state power for execution of similar tasks, secondly, under given conditions opportunities of complex use of infrastructural objects by small business enterprises are not provided that decreases the level of the entrepreneurial activity at early stages of business development and as a result the level of entrepreneurship infrastructure effective use.

Solution of the given problem supposes distribution of powers and responsibilities in the state regulation of the small entrepreneurship infrastructural provision among state authority bodies at regional level. At the same time linear 
powers in the formation and responsibility for the creation, development and use of small entrepreneurship complex infrastructure use should be redirected to regional departments of The Union of industrialists and entrepreneurs that allows to enhance the efficiency of expert activity in time of measure taking on the development of entrepreneurial infrastructure. At lower hierarchical levels of the small regional entrepreneurship infrastructural development management, linear powers and responsibility are expedient to distribute as following: formation and use of social and innovative infrastructures are achieved by regional Ministry of justice (or its analogue), engineering and production infrastructure - Ministry of industry (or analogous department), transport and logistics - Ministry of transport and road economy or analogous department in the structure of the region's government. It is expedient to provide regional departments of small and medium business development with apparatus powers in solution of private problems of infrastructural development within achievement of co-operation with the authorized state bodies which would also allow to enhance the efficiency of expert activities in the processes of small entrepreneurship infrastructure creation and development.

The second most important task within distribution of powers and responsibility is the establishment of limits to state interference in the processes of actual formation, development and use of infrastructural units. State support is necessary for the provision of uninterrupted functioning of the transport and logistics infrastructure for small business which are the elements of economic safety system as a result of which corresponding managing companies should be either a state's property or joint-stock company with 100\% state participation. Finance, engineering and industrial infrastructures vice versa should belong to the private management under conditions of norm observance determined within mechanisms of state regulation of the given sphere which will allow to enhance clients' value of corresponding infrastructural units from the point of small business. Units of social, information, managing and innovative infrastructures should be in combined property and their management should be conducted within private-state and state-private partnership the way that small business enterprises functioning in region could become a minority shareholder of the appropriate managing companies which will allow the small entrepreneurship representatives to take direct part in decision making.

The conducted analysis of small entrepreneurial problems development showed that one of the key problems of the lack of high efficiency in state support of entrepreneurial infrastructure is its irrational use by subjects of small business that is caused by two main reasons. Firstly, small entrepreneurship infrastructure is not always formed in regions in accordance with small business enterprises' need that leads to the fact that the latter experience difficulties with its use within reproduction process, secondly, small business subjects often irrationally use the created infrastructural units. As a result it is necessary to develop a measuring set of instruments which would allow to compare alternative variants of the formation and development of infrastructural provision, budget, social and commercial efficiency of which depends on the three main components: the level of small business provision, presence of infrastructural units and synergetic effect occurring while using the existing resources with application of infrastructural provision by small business subjects. As the conducted research showed, in order to evaluate potential result, it is necessary to carry out research on opportunities of different combination of resources, resource provision being projected and synergetic effect with matrix that could be formalized to enhance the effectiveness of state regulation by the following:

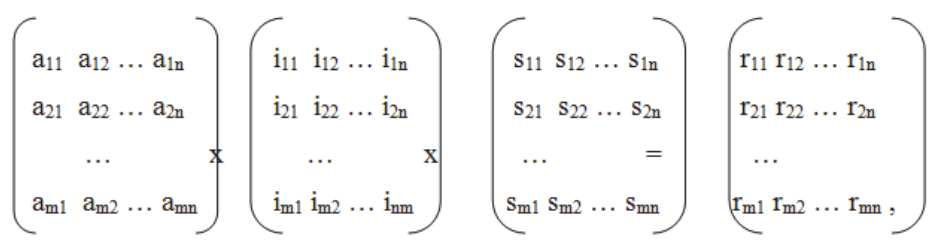

where $a_{i j}$ - the level of small enterprises of $j$ branch provision with i type of resource, mark $(0 \div 10$, where 0 - resource is absent, 10 - resource is present in quantity significantly exceeding the required);

$\mathrm{i}_{\mathrm{ij}}$ - the level of small enterprises of $\mathrm{j}$ branch provision with $\mathrm{i}$ type of infrastructural units allowing to enhance efficiency of appropriate resource use, mark $(0 \div 10$, where 0 - infrastructural units are absent; 10 - infrastructural units are in quantity exceeding the required);

$\mathrm{Sl}_{\mathrm{j}}-$ the synergetic effect occurring while using infrastructural units of the first type by small enterprises of $\mathrm{j}$ branch, mark (- $\div \div+5$, where -5 -significant negative synergetic effect; $+5-$ significant positive synergetic effect);

$r[11 \div \mathrm{mn}]$ - the resultant matrix of the effectiveness of the small entrepreneurship infrastructural provision use diagnostics. 
The received final matrix, characterizing the effectiveness and quality of the small entrepreneurship infrastructural units use, is expedient to use at stages of process planning of the infrastructural provision development aimed at realization of the given processes variation modeling which would allow to enhance the efficiency of state regulation of infrastructural provision and also at the control stage of its results use that will allow to carry out plan-fact analysis in the given sphere.

\section{Conclusions}

The conducted research showed that the maximum economic effectiveness and infrastructural provision of state regulation efficiency is provided when two-parameter event evaluation on its creation, development and use is held which formed the necessity of its appropriate criteria evaluation systematization.

Key indices of economic efficiency, effectiveness and quality indirectly characterizing small entrepreneurship infrastructural use, do not coincide for the small business units and the state which dictates the necessity of both types of indicators use in evaluation of entrepreneurial infrastructural territory perspectives which will allow to simultaneously enhance its demand by entrepreneurs and the efficiency and effectiveness of the given sphere state regulation.

Realization of the suggested set of instruments for the perfection of state regulation of small entrepreneurship infrastructural provision supposes the correction of state influence at the stages of planning, organization, motivation and control of management cycle. And at the planning stage it is necessary to hold variation scene prediction of infrastructural entrepreneurship development taking into account the existing small business enterprises provision with resources and possible generation of synergetic effect and also to considerate in the first place the infrastructural development influence on internal dynamics of entrepreneurial medium. Correction of state regulation of the small business infrastructural provision organization supposes the necessity of state investments realization according to the exposed priority sequence of infrastructural development the way that within motivation stage realization in the first place to form infrastructural elements allowing to enhance the level of entrepreneurial activity (social, innovative, and managing infrastructural elements). Furthermore, at the control stage it is necessary to use multi-parameter evaluation of economic efficiency, effectiveness and quality of infrastructural units application by small business subjects which, on the one hand, will allow to receive infrastructural provision and, on the other hand, to pay needed attention to the occurring problem of the multicollinearity of factor influence.

Forecasting of the improved approach to state regulation of the entrepreneurship infrastructural provision inculcation was held by parameters of the entrepreneurial activity level TEA and the efficiency of investments in small entrepreneurship infrastructural development in accordance with the following scenarios:

- current, within which change of the formed tendencies of small entrepreneurship infrastructural provision is not supposed;

- dynamic, within which preservation of the formed tendencies of state regulation of small entrepreneurship infrastructural provision with capital investments increase in the given sphere is supposed;

- innovative, within which realization of the presented in the given research instruments and mechanisms of state regulation of small entrepreneurship infrastructural provision is supposed.

Results of forecasting by three given scenarios are presented in Fig. 3.

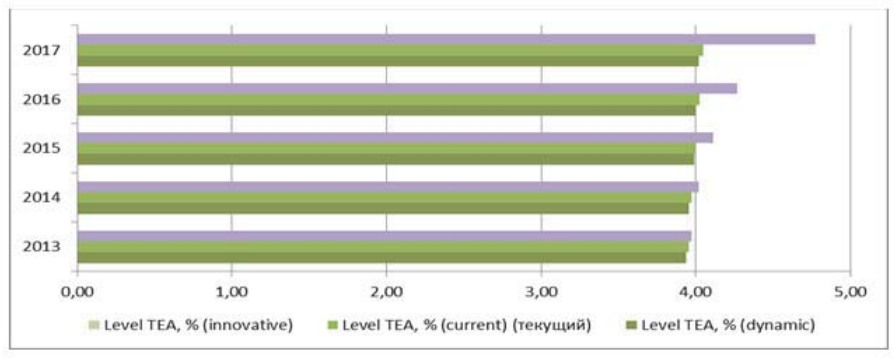

Fig. 3. Dynamics of average Russian level of entrepreneurial activity TEA in 2013-2017 by scenarios

As it is clear form the given picture, during realization of innovative scenario significant increase of entrepreneurial activity level is provided; efficiency of investments in infrastructural development in case of the current scenario realization in 
2017 will equal $38.89 \%$, dynamic scenario realization $-26.22 \%$ (in both cases dynamics of infrastructural efficiency is negative), whereas in case of realization of innovative scenario, infrastructural efficiency in 2017 will equal 114.13\% with preservation of the stable enhancing tendency of effectiveness in the forecast period.

\section{References}

Bagautdinova N.G., Gafurov I.R., Kalenskaya N.V., NovenkovaA.Z Territorial Marketing as Successful Strategy for Regional Development. 3rd Annual International Conference Qualitative and Quantitative Economics Research (QQE 2013): 18-23, 2013.

Bagautdinova N.G., Gafurov I.R., Kalenskaya N.V., Novenkova A.Z. The Regional Development Strategy Based on Territorial Marketing (The Case of Russia). World Applied Sciences Journal 18 (Special Issue of Economics): 179-184, 2012;

Melnik A.N., Mustafina O.N. The Organization of Russian Power Market in Modern Conditions // Middle-East Journal of Scientific Research 13. - 2013. - P. 91-94.

Hanssens, H., Derudder, B., Witlox, F. Are advanced producer services connectors for regional economies? An exploration of the geographies of advanced producer service procurement in Belgium // Geoforum, 2013. pp. 12-21.

Huning, S., Naumann, M., Bens, O., Hüttl, R.F. Transformations of modern infrastructure planning in rural regions: The case of water infrastructures in Brandenburg, Germany // European Planning Studies19 (8) , 2011. pp. 1499-1516

Melnik A.N., Lukishina L.V., Khabibrakhmanov R.R. Methodological Foundations of the Formation of the Energy Strategy of an Enterprise // World Applied Sciences Journal. 2013. v. 23 (8). Pp. 1085-1089.

Melnik, A.N., Sadriev A.R. Problems and prospects of the formation of clusters in the power engineering // World Applied Sciences

Journal. - 2013. - v. 27. Pp. 194-197. Gibadullin M.Z. Fazlieva E.P. Nurieva A.R. Grigoryeva L.L Territorial Aspects of Migration Processes in Russia// Mediterranean Journal of Social Sciences.- Vol.5, No12, (2014) -pp.93-96.

Nugumanova L.F., Novenkova A.Z., Abdulganiev F.S., Toropova N.V. The Role of Gender Factors in the Formation of Investment Attractiveness of the Territoryl/ Mediterranean Journal of Social Sciences.- Vol.5, No12, (2014)-pp.97-102.

Sadriev A.R. Problems and prospects of networking mechanism using in energy systems innovation development // Middle-East Journal of Scientific Research. - 2013. V. 17 (10). - pp. 1453-1456.

Panasyuk M.V., Pudovik E.M., Sabirova M.E.. 2013. Optimization of regional passenger bus traffic network // Procedia Economic and finance. Volume 5, pp. 589-596.

Bagautdinova N.G., Galieva G.T., Pakhmutov Ya.O., Pratchenko O.V. Methods of Regulation of Processes of Innovation Business Development// Mediterranean Journal of Social Sciences.- Vol.5, No12, (2014)-pp.75-80.

Kundakchyan R.M., Zulfakarova L.F. Current issues of optimal capital structure based on forecasting financial performance of the company. Life Science Journal 2014; 11(6s): 368-371.

Huning, S., Naumann, M., Bens, O., Hüttl, R.F. Transformations of modern infrastructure planning in rural regions: The case of water infrastructures in Brandenburg, Germany // European Planning Studies19 (8) , 2011. pp. 1499-1516

Parr, J.B. The Regional Economy, Spatial Structure and Regional Urban Systems // Regional Studies. 2013. 